\title{
Effects of Temperature on the Microstructure and Magnetic Property of Cr-Doped ZnO DMS Prepared by Hydrothermal Route Assisted by Pulsed Magnetic Fields
}

\author{
Shiwei Wang, Min Zhong, Cong Liu, Ying Li, Mingyuan Zhu, Hongming Jin, and Yemin Hu \\ Laboratory for Microstructures/School of Materials Science and Engineering, Shanghai University, 149 Yanchang Road, \\ Shanghai 200072, China \\ Correspondence should be addressed to Yemin Hu; huyemin@shu.edu.cn \\ Received 12 July 2013; Accepted 24 August 2013 \\ Academic Editor: Sirilak Sattayasamitsathit \\ Copyright (C) 2013 Shiwei Wang et al. This is an open access article distributed under the Creative Commons Attribution License, \\ which permits unrestricted use, distribution, and reproduction in any medium, provided the original work is properly cited. \\ In the present work, $\mathrm{Cr}$-doped $\mathrm{ZnO}$ diluted magnetic semiconductor was synthesized by hydrothermal method under pulsed \\ magnetic fields. The samples were characterized by XRD, SEM, VSM, Raman, and XPS techniques. Results demonstrated that Zn \\ ions in the $\mathrm{ZnO}$ crystal lattice were partially displaced by Chromium (III) ions. All samples show room temperature ferromagnetism \\ which was enhanced by pulsed magnetic fields. The mechanism of ferromagnetism of Cr-doped $\mathrm{ZnO}$ particles was discussed.
}

\section{Introduction}

Over the past few decades, diluted magnetic semiconductors (DMSs) have been attracted considerable interests due to their versatile potential applications in spin electronic devices, such as spin field-effect transistors; nonvolatile memory devices; and quantum computer [1-7]. Zinc oxide has been considered as one of the promising DMS candidates for its superior semiconductor performance [8]. It also possesses outstanding piezoelectric property and excellent chemical stability $[9,10]$. Since the study of Dietl et al. [1] predicted that the Curie temperature (Tc) of TMs-doped ZnO DMS could be above room temperature (RT), and furthermore Sato and Katayama-Yoshida [11] predicted that ZnO-doped with $\mathrm{Cr}, \mathrm{V}, \mathrm{Fe}, \mathrm{Ni}$, and Co could be RT ferromagnetic (FM), TMs-doped ZnO DMSs have been extensively investigated. A challenge for the application of ZnO DMSs is to enhance their room temperature magnetic property. Our group recently has successfully developed a novel hydrothermal method under high magnetic field to prepare a series of transition metal ions $\left(\mathrm{Cr}^{3+}, \mathrm{Mn}^{2+}\right.$, and $\left.\mathrm{Co}^{2+}\right)$-doped $\mathrm{ZnO}$ DMSs [1214]. Magnetic cations-doped $\mathrm{ZnO}$ synthesized under high magnetic field shows better FM behavior. It is believed that the magnetic field provided an external energy to facilitate metal ions migrating into the $\mathrm{ZnO}$ lattice and caused more lattice defects. The hybridization effect between the metal ions and lattice defects changed the magnetic property of DMSs.

Among the doping elements, $\mathrm{Cr}$ draws the most attention $[15,16]$. Currently, many methods have been reported to fabricate Cr-doped ZnO DMSs [17-21], such as vapors phase growth, thermal decomposition, seed-mediated, and reverse micelle. However, in some reports, the results are opposite even the samples were prepared in the same way, for example, some samples exhibited paramagnetic (PM), but some exhibited FM. It indicates that the magnetic performance of $\mathrm{ZnO}$ DMSs is very sensitive to the reaction conditions. Therefore, the present work is to introduce an external high magnetic field and well control the chemical reaction conditions to enhance the magnetic property of DMSs. We intend to investigate the effects of the magnetic field together with the reaction temperature on the microstructure, morphology, and magnetic properties of Cr-doped ZnO DMS prepared by hydrothermal method under high pulsed magnetic fields.

\section{Experimental}

Zinc chloride $\left(\mathrm{ZnCl}_{2}\right)$, chromic chloride $\left(\mathrm{CrCl}_{3} \cdot 6 \mathrm{H}_{2} \mathrm{O}\right)$, aqueous ammonium $\left(\mathrm{NH}_{3} \cdot \mathrm{H}_{2} \mathrm{O}\right)$, and ammonium chloride $\left(\mathrm{NH}_{4} \mathrm{Cl}\right)$ were of used. All chemical reagents were analytical 


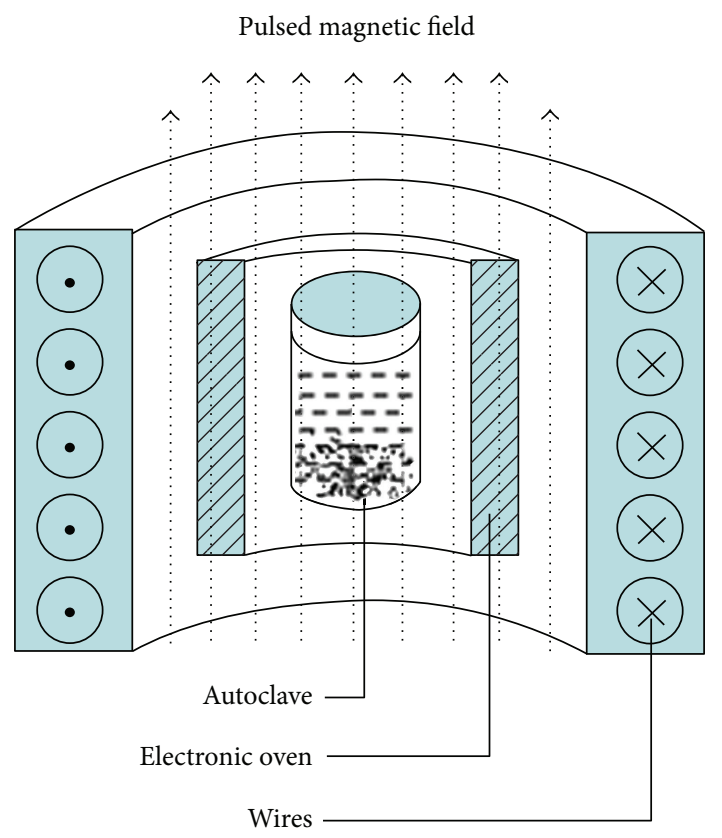

FIGURE 1: The schematic diagram of pulsed magnetic fields assisting hydrothermal system.

grade without any further purification. A $6 \mathrm{~mL} 2 \mathrm{M}$ zinc chloride solution; $6 \mathrm{~mL} 0.04 \mathrm{M}$ chromic chloride solution; and $8 \mathrm{~mL}$ of buffer solution $\left(\mathrm{pH}=10.0, \mathrm{NH}_{3} / \mathrm{NH}_{4} \mathrm{Cl}(\mathrm{aq})\right.$ ) were mixed sequentially. The nominal content of $\mathrm{Cr}$ ions in $\mathrm{ZnO}$ was about 2 at $\%$. After stirring for $1 \mathrm{~h}$, the mixture was transferred into a $25.0 \mathrm{~mL}$ Teflon-lined titanium alloy autolave. The autoclaves were placed in an electric oven and heated at $100-180^{\circ} \mathrm{C}$ range of temperature for 4 hours with or without pulsed magnetic fields ( $4 \mathrm{~T}$ ). The experimental setup is illustrated as in Figure 1. The mixture was then filtrated, and the solid product was washed twice with distilled water and once with absolute ethanol. It was then dried in $80^{\circ} \mathrm{C}$ air for $8 \mathrm{~h}$. Samples prepared under $4 \mathrm{~T}$ pulsed magnetic fields at $\mathrm{N}^{\circ} \mathrm{C}$ were referred to as $\mathrm{S}-\mathrm{N}^{\circ} \mathrm{C}-4 \mathrm{~T}$ and those without pulsed magnetic fields as $\mathrm{S}-\mathrm{N}^{\circ} \mathrm{C}-0 \mathrm{~T}$. Pure $\mathrm{ZnO}$ was prepared with the similar process at $180^{\circ} \mathrm{C}$.

The microstructure of the samples were characterized by X-ray diffraction meter (XRD, D/max $2550 \mathrm{~V}$, Rigaku, Cu $\mathrm{K} \alpha, \lambda=0.15406 \mathrm{~nm}$ ). The morphologies of above-prepared samples were observed by scanning electron microscopy (SEM, JSM-6700F, JEOL). The magnetic hysteresis loops of the specimens were estimated by vibrating sample magnetometer (VSM, Lakeshore 7407). Raman scattering (RS, inVia plus, Renishaw) was used to record the information about the crystal defect and change of free carriers in the samples. The valence state of element was analyzed by $\mathrm{X}$-ray photoelectron spectroscopy (XPS) (Thermo ESCALAB 250).

\section{Results and Discussions}

Figure 2 shows XRD patterns of $\mathrm{Cr}$-doped $\mathrm{ZnO}$ particles prepared at different reaction temperature with and without pulsed magnetic fields. For all samples, all diffraction peaks

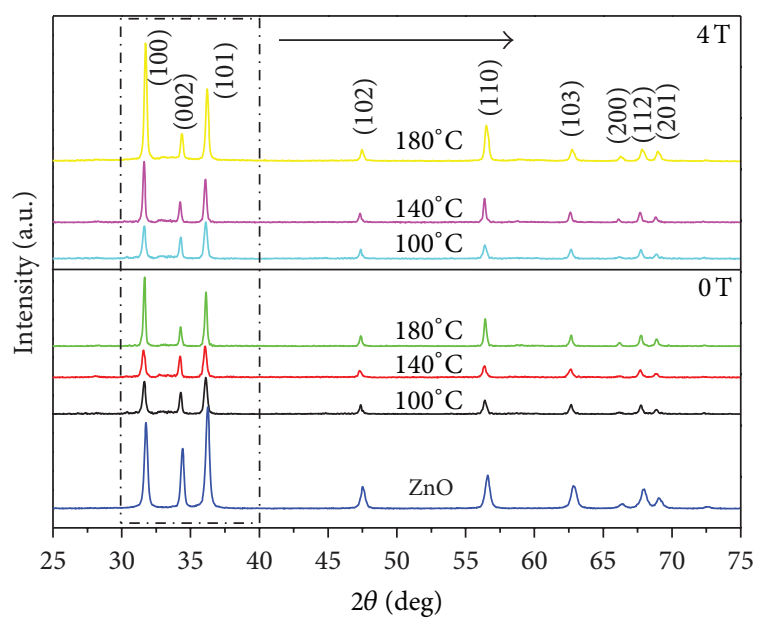

(a)

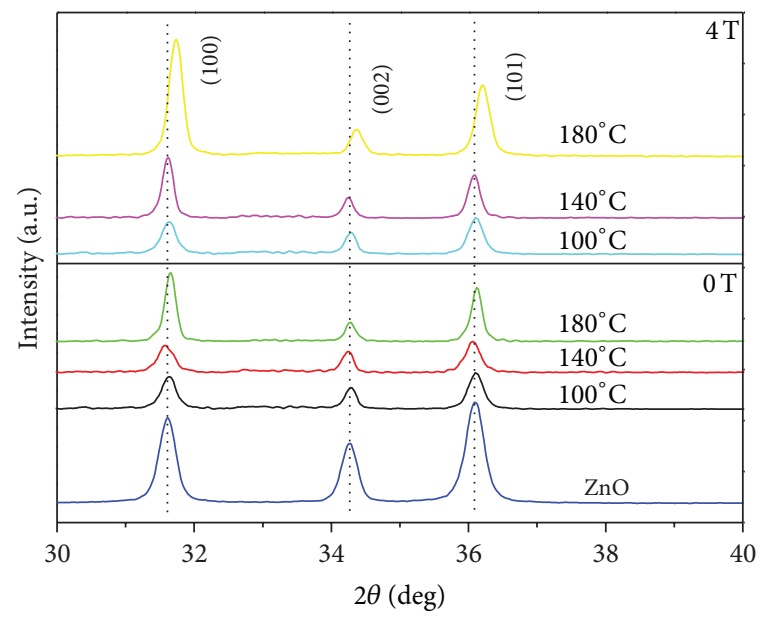

(b)

FIgURE 2: The XRD patterns of the samples.

correspond well to the hexagonal wurtzite $\mathrm{ZnO}$ crystal structure (space group $\mathrm{P}_{3} \mathrm{mc}$; JCPDS card number 36-1451). No other phases or impurities were found in the crystals. Compared with pure $\mathrm{ZnO}$, main peaks of $\mathrm{Cr}$-doped $\mathrm{ZnO}$ shifted slightly to higher angles. It indicated that the distortion in the lattice was brought by $\mathrm{Cr}$ doping into the $\mathrm{ZnO}$ crystal lattice. As the radius of $\mathrm{Cr}^{3+}$ ions $(0.63 \AA)$ is smaller than that of $\mathrm{Zn}^{2+}$ ions $(0.74 \AA)$, the lattice volume of $\mathrm{Cr}^{3+}$-doped $\mathrm{ZnO}$ would be decreased. The higher the content of $\mathrm{Cr}^{3+}$ in $\mathrm{ZnO}$ is, the smaller the lattice constants are, and the greater the distortion of $\mathrm{ZnO}$ crystal lattice will be. It was observed in Figure 2(b) that both higher reaction temperature and pulsed magnetic fields resulted in enhanced shifts of the main peaks of Cr-doped $\mathrm{ZnO}$. These phenomena demonstrated that a combination of high reaction temperature and pulsed magnetic fields were favorable for $\mathrm{Cr}^{3+}$ incorporated $\mathrm{ZnO}$.

The morphologies of Cr-doped $\mathrm{ZnO}$ DMS are shown in Figure 3. Table 1 gave the average sizes of the samples. The sizes of sample S- $100^{\circ} \mathrm{C}-0 \mathrm{~T}$ were about $50-100 \mathrm{~nm}$ in diameter and $1-3 \mu \mathrm{m}$ in length. For sample $\mathrm{S}-100^{\circ} \mathrm{C}-4 \mathrm{~T}$, the diameter and length increased to about $100-150 \mathrm{~nm}$ and 


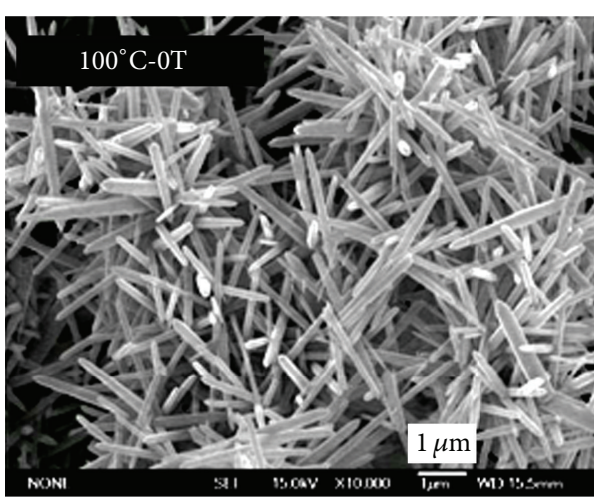

(a)

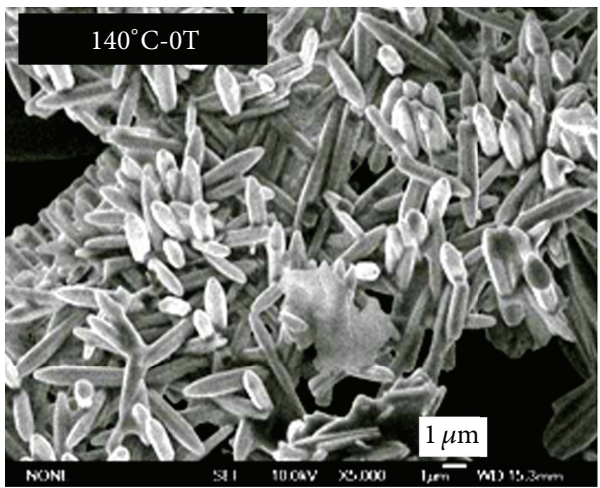

(c)

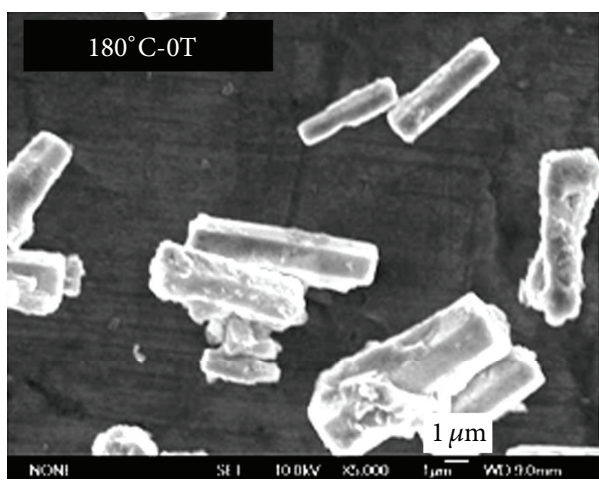

(e)

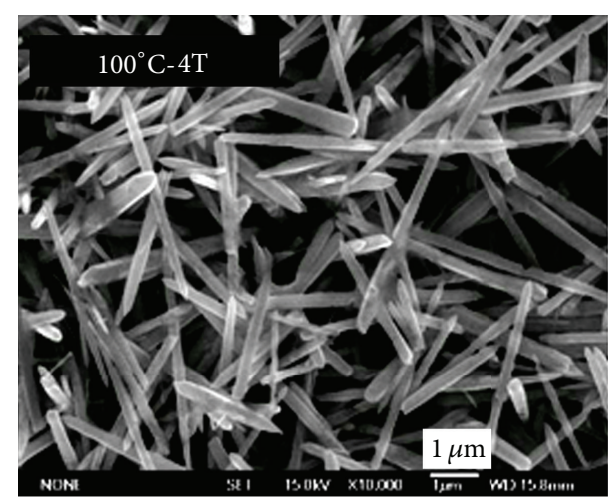

(b)

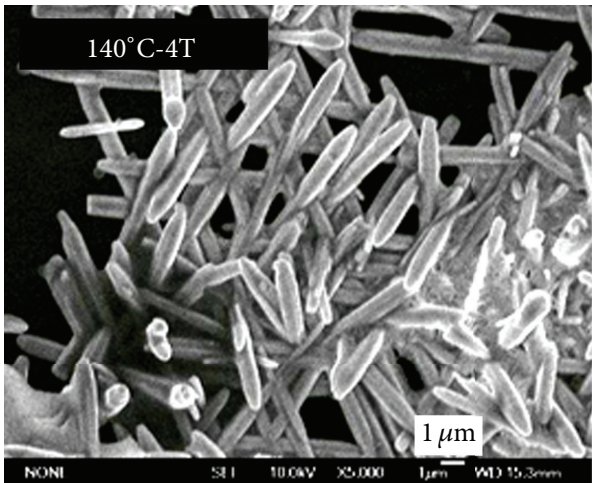

(d)

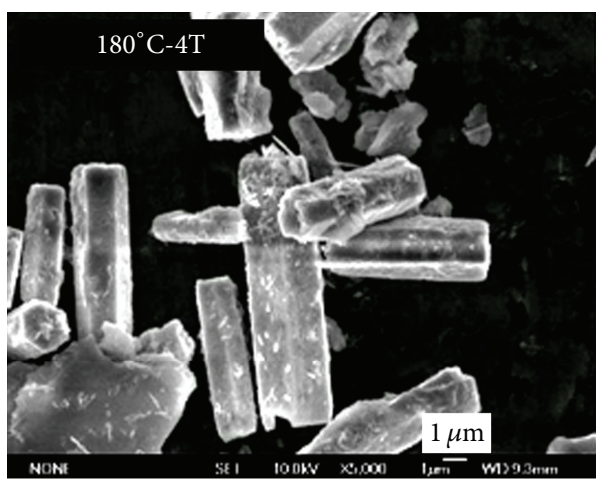

(f)

Figure 3: The SEM images of the samples: (a) $100^{\circ} \mathrm{C}-0 \mathrm{~T}$, (b) $100^{\circ} \mathrm{C}-4 \mathrm{~T}$, (c) $140^{\circ} \mathrm{C}-0 \mathrm{~T}$, (d) $140^{\circ} \mathrm{C}-4 \mathrm{~T}$, (e) $180^{\circ} \mathrm{C}-0 \mathrm{~T}$, and (f) $180^{\circ} \mathrm{C}-4 \mathrm{~T}$.

TABLE 1: Average size of the samples.

\begin{tabular}{lccc}
\hline \multirow{2}{*}{ Field (T) } & \multicolumn{3}{c}{ Sizes parameters (length, diameter) } \\
& $100^{\circ} \mathrm{C}$ & $1400^{\circ} \mathrm{C}$ & $180^{\circ} \mathrm{C}$ \\
\hline 0 & $1-3 \mu \mathrm{m}, 50-100 \mathrm{~nm}$ & $5 \mu \mathrm{m}, 700 \mathrm{~nm}$ & $7 \mu \mathrm{m}, 1 \mu \mathrm{m}$ \\
4 & $4 \mu \mathrm{m}, 100-150 \mathrm{~nm}$ & $6 \mu \mathrm{m}, 800 \mathrm{~nm}$ & $8 \mu \mathrm{m}, 1.5 \mu \mathrm{m}$ \\
\hline
\end{tabular}

$4 \mu \mathrm{m}$, respectively. $\mathrm{ZnO}$ particles prepared at $140^{\circ} \mathrm{C}$ were larger than those prepared at $100^{\circ} \mathrm{C}$. The sizes of sample S$140^{\circ} \mathrm{C}-4 \mathrm{~T}$ were larger and more uniform than sample $\mathrm{S}$ $140^{\circ} \mathrm{C}-0 \mathrm{~T}$. When reaction temperature was raised to $180^{\circ} \mathrm{C}$, the sizes of $\mathrm{ZnO}$ particles became much larger, especially their diameters. It could be concluded that pulsed magnetic fields accelerated the growing of $\mathrm{ZnO}$ particles, by supplying additional energy to the particle crystalizing process.

Figure 4 shows the magnetic hysteresis loops $(\mathrm{M}-\mathrm{H})$ of Cr-doped $\mathrm{ZnO}$ DMS measured at room temperature. All samples exhibited room temperature ferromagnetism. The saturation magnetizations (Ms) of the samples varied in the range of $0.0227-0.0716 \mathrm{emu} / \mathrm{g}$, as listed in Table $2 . \Delta$ represented the difference of Ms of two of the samples, prepared at the same reaction temperature with and without pulsed magnetic fields, respectively. Ms increased with reaction temperature increased from $100^{\circ} \mathrm{C}$ to $180^{\circ} \mathrm{C}$. For the samples of the same reaction temperature, the Ms of the samples prepared under $4 \mathrm{~T}$ pulsed magnetic fields were higher than that of the samples under no pulsed magnetic fields. 


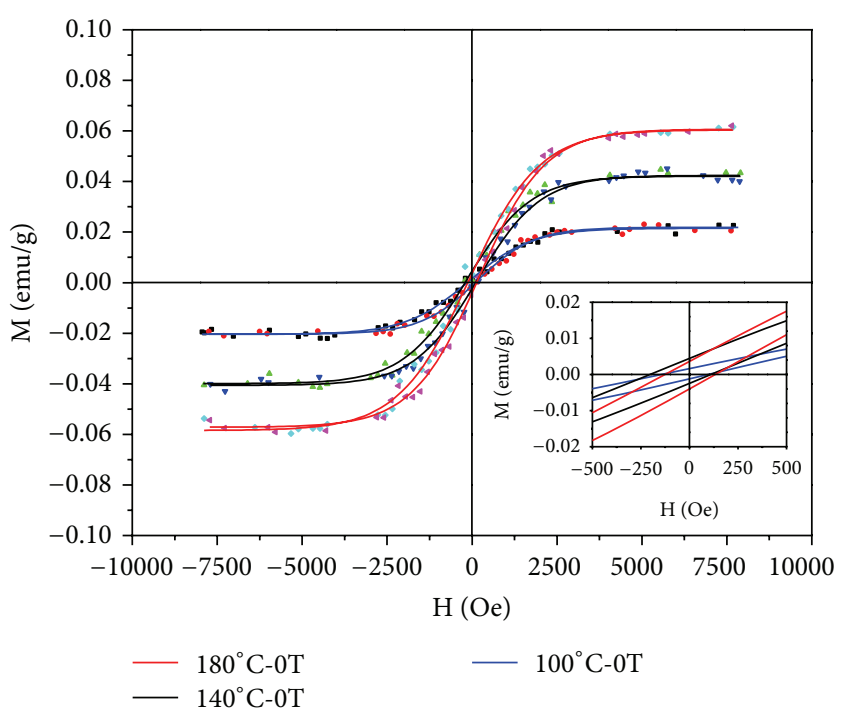

(a)

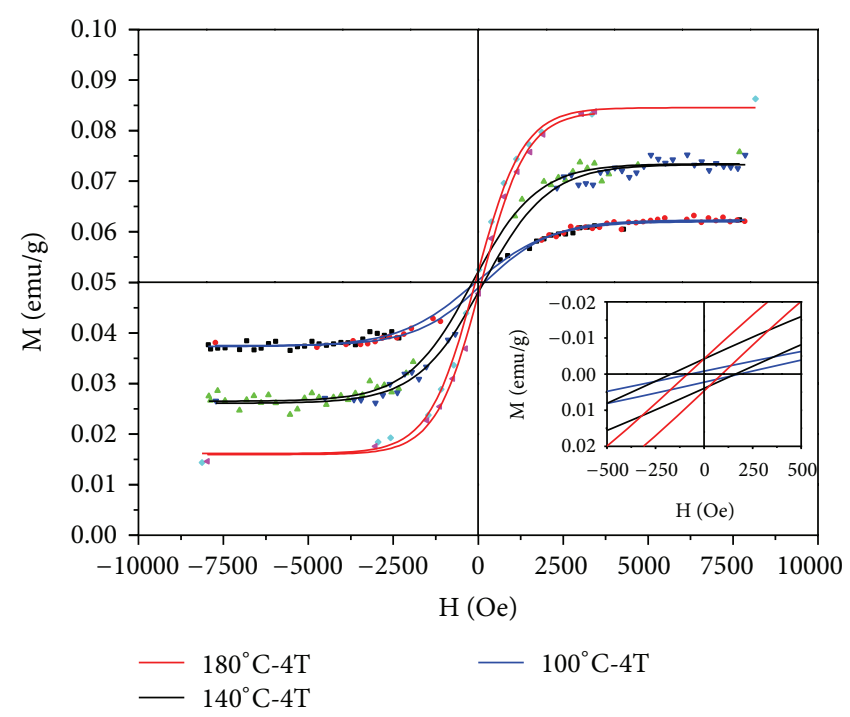

(b)

FIgURE 4: The magnetic hysteresis loops of the Cr-doped ZnO particles: (a) $0 \mathrm{~T}$ and (b) $4 \mathrm{~T}$.

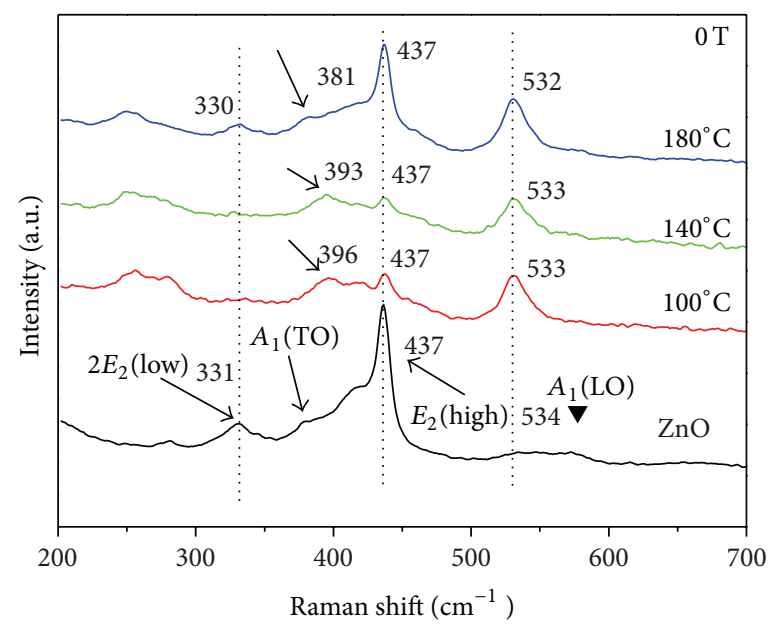

(a)

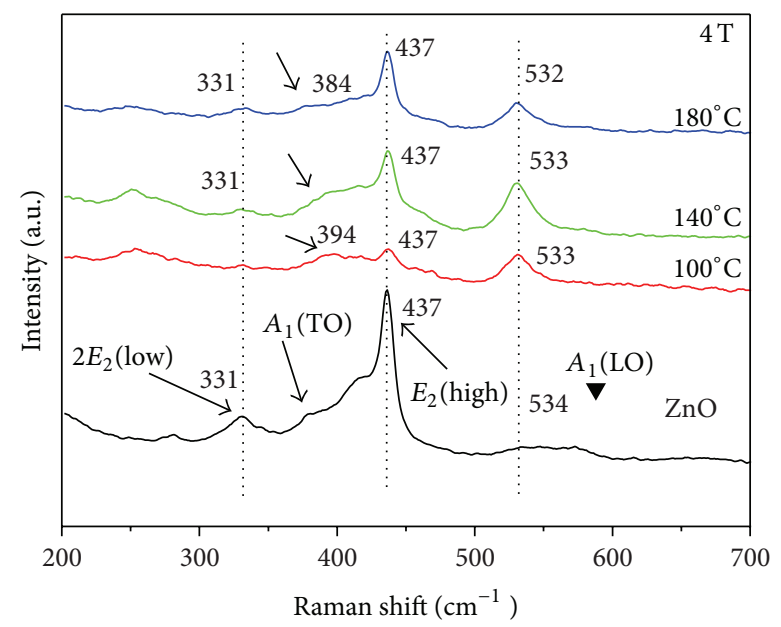

(b)

FIgURE 5: The Raman spectra of the samples.

The results indicated that pulsed magnetic fields do enhance the ferromagnetic properties of Cr-doped $\mathrm{ZnO}$ DMS. As mentioned before, both higher reaction temperature and applying pulsed magnetic fields affect the hydrothermal fabrication process of $\mathrm{Cr}$-doped $\mathrm{ZnO}$ DMS, more $\mathrm{Cr}^{3+}$ ions were incorporated into $\mathrm{ZnO}$ lattice. Here $\mathrm{M}$-H loops demonstrated that the more the $\mathrm{Cr}^{3+}$ ions-doped into $\mathrm{ZnO}$, the stronger the room temperature ferromagnetism of $\mathrm{ZnO}$ DMS. According to the BMP model, the occurrence of strong electronic coupling between bound polarons and $\mathrm{Cr}^{3+}$ ions would form bound magnetic polarons [22], which was suggested to play an important role in the ferromagnetic origin of Cr-doped ZnO DMS [23, 24].

Raman scattering is a versatile technique for detecting the defects and lattice disorder in the host lattice [25]. Figure 5
TABLE 2: The saturation magnetizations of the samples.

\begin{tabular}{lccc}
\hline & & $\mathrm{Ms}(\mathrm{emu} / \mathrm{g})$ & \\
& $100^{\circ} \mathrm{C}$ & $140^{\circ} \mathrm{C}$ & $180^{\circ} \mathrm{C}$ \\
\hline $0 \mathrm{~T}$ & 0.0227 & 0.0418 & 0.0592 \\
$4 \mathrm{~T}$ & 0.0279 & 0.0515 & 0.0716 \\
$\Delta$ & 0.0052 & 0.0097 & 0.0124 \\
\hline
\end{tabular}

illustrates the unpolarized Raman spectra of the Cr-doped and pure $\mathrm{ZnO}$ samples in the range $200-700 \mathrm{~cm}^{-1}$ at room temperature. The spectra revealed standard phonon modes at $331,381,437$, and $534 \mathrm{~cm}^{-1}$ of pure $\mathrm{ZnO}[26,27]$. For the $\mathrm{Cr}^{+3}$-doped samples, there was a shift towards the lowfrequency, depending on the structural disorder and crystal 


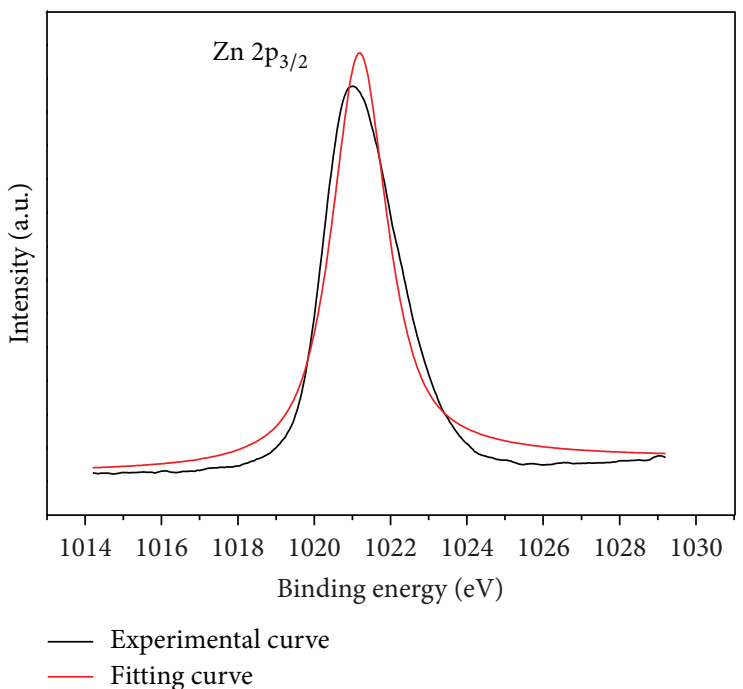

(a)

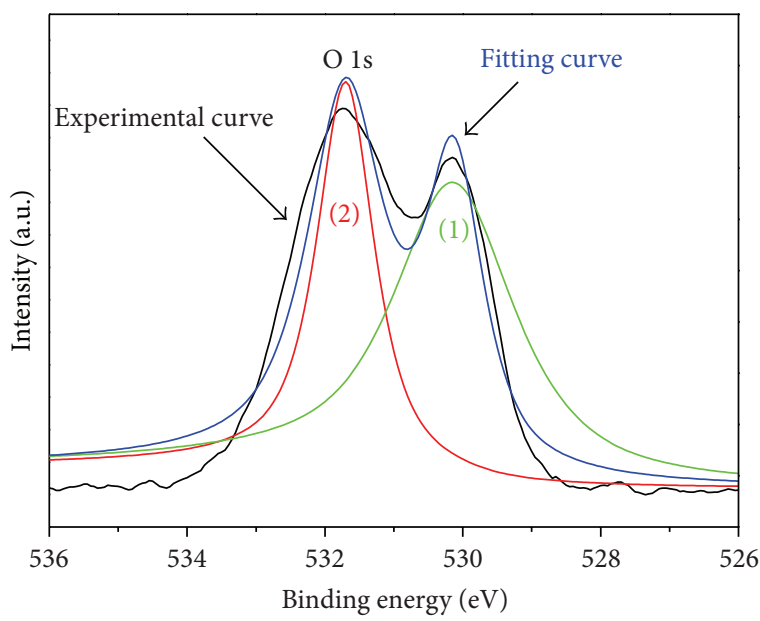

(b)

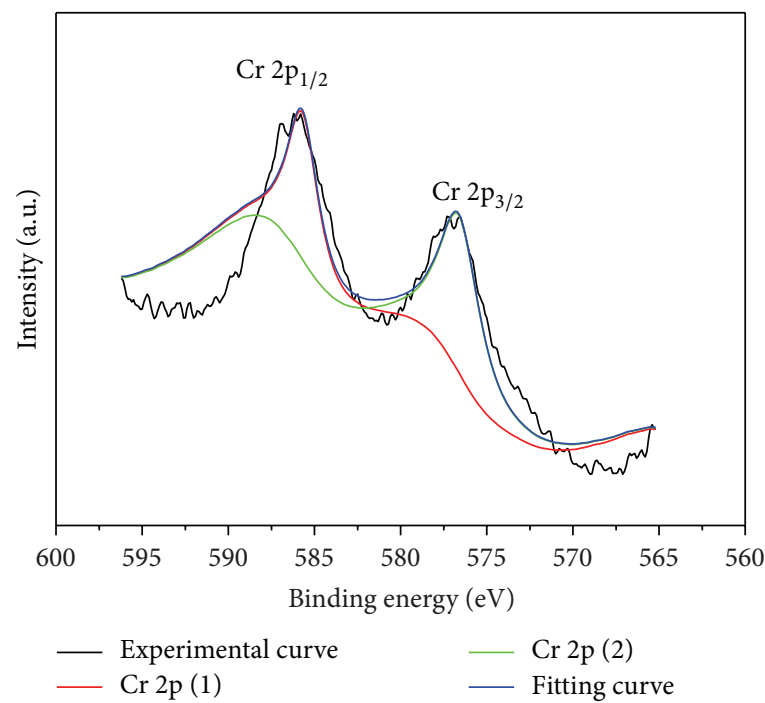

(c)

FIGURE 6: XPS spectrum of Cr-doped ZnO DMS.

defects of the samples. The zone-center optical phonons of the wurtzite structure of $\mathrm{ZnO}$ could be classified according to the following irreducible representations:

$$
\Gamma_{\text {opt }}=1 A_{1}+2 B_{1}+1 E_{1}+2 E_{2} .
$$

The $B_{1}$ modes were silent in Raman scattering, whereas $A_{1}$ and $E_{1}$ modes were polar and hence exhibit different frequencies for the transverse-optical (TO) and longitudinaloptical (LO) phonons [28]. The nonpolar $E_{2}$ modes have two frequencies, namely, $E_{2}$ (high) and $E_{2}$ (low), associated with the motion of oxygen $(\mathrm{O})$ atoms and zinc $(\mathrm{Zn})$ sublattice, respectively [29]. For all the samples, the sharpest and strongest peak at $437 \mathrm{~cm}^{-1}$ could be assigned to $E_{2}$ (high), which was the strongest mode in wurtzite crystal structure. The peaks at 331 and $380 \mathrm{~cm}^{-1}$ were assigned to the secondorder vibration mode and $A_{1}$ (TO) mode, respectively.
The peak at $437 \mathrm{~cm}^{-1}$ was sensitive to the crystal stress, while the peak at $580 \mathrm{~cm}^{-1}$ was sensitive to the change of free carrier concentration $[25,30]$. As Wang et al. [31] reported that the intensity of $A_{1}$ (LO) mode decreased with the increase in carrier concentration. In the present work, the $A_{1}$ (LO) modes of all the $\mathrm{Cr}$-doping $\mathrm{ZnO}$ samples disappeared, which indicated the increase of free carrier induced by $\mathrm{Cr}$ doping. Kittilstved et al. [32] suggested that defect-bound carriers such as point defects hybridization with magnetic dopants would induce ferromagnetism in transition metal (TM) ionsdoped $\mathrm{ZnO}$ DMS. In this study, it was found that pulsed magnetic fields induced $\mathrm{Cr}^{3+}$ ions substitute into the $\mathrm{ZnO}$ crystal lattice. Since more defects were introduced into the crystal lattice under pulsed magnetic fields, it resulted in the more hybridization between the defects and $\mathrm{Cr}$ dopants, which may be responsible for the result of room temperature 
ferromagnetism and the enhancement of saturation magnetization of the pulsed magnetic fields processed $\mathrm{Cr}$-doped $\mathrm{ZnO}$ DMS.

In order to investigate the chemical state of the host and dopant elements, the XPS studies were undertaken. XPS analysis shows the presence of $\mathrm{Zn}, \mathrm{Cr}$, and $\mathrm{O}$ elements in $\mathrm{Cr}$-doped $\mathrm{ZnO}$. The overlapped bands were resolved into separated peaks by using XPS PEAK41 software. The Zn 2 $\mathrm{p}_{3 / 2}$, $\mathrm{O} 1 \mathrm{~s}, \mathrm{Cr} 2 \mathrm{p}_{3 / 2}$, and $\mathrm{Cr} 2 \mathrm{p}_{1 / 2}$ XPS spectral regions of the Crdoped $\mathrm{ZnO}$ DMS prepared at $100^{\circ} \mathrm{C}$ without pulsed magnetic fields were shown in Figure 6. Based on the Gauss fitting, the $\mathrm{Cr} 2 \mathrm{p}_{3 / 2}$ peak position was at $576.6 \mathrm{eV}$ in the $\mathrm{Cr}$-doped $\mathrm{ZnO}$ nanoparticle. It was clearly different from $574.2 \mathrm{eV}$ of Cr metal and $576.0 \mathrm{eV}$ of $\mathrm{Cr}^{2+}$, but quite close to the peak position of $\mathrm{Cr} 2 \mathrm{p}_{3 / 2}(576.7 \mathrm{eV})$ in $\mathrm{Cr}_{2} \mathrm{O}_{3}$ [33]. It suggested that $\mathrm{Cr}^{+3}$ ions were actually the incorporated dopants.

\section{Conclusions}

Cr-doped $\mathrm{ZnO}$ DMSs were prepared by the hydrothermal method at different temperature under pulsed magnetic fields. All samples kept the hexagonal wurtzite structure and possessed room temperature ferromagnetism. High reaction temperature and pulsed magnetic fields both promoted higher $\mathrm{Cr}^{+3}$ ions incorporation. The crystals grew bigger as the temperature rose and pulsed magnetic fields were applied. Both higher reaction temperature and applying pulsed magnetic fields enhanced the magnetic property of Cr-doped ZnO DMS. The ferromagnetism may be results of free carrier induced by $\mathrm{Cr}$ doping. It was demonstrated that the $\mathrm{Zn}^{+2}$ ions were displaced by the $\mathrm{Cr}^{+3}$ ions in the doping process.

\section{Conflict of Interests}

The authors declare that there is no conflict of interests regarding the publication of this paper.

\section{Acknowledgments}

The authors thank the project supported by Shanghai Science and Technology Commission (11nm0501600) and the Analysis and Research Center of Shanghai University for their technical supports.

\section{References}

[1] T. Dietl, H. Ohno, F. Matsukura, J. Cibert, and D. Ferrand, "Zener model description of ferromagnetism in zinc-blende magnetic semiconductors," Science, vol. 287, no. 5455, pp. 10191022, 2000.

[2] S. J. Pearton, C. R. Abernathy, M. E. Overberg et al., "Wide band gap ferromagnetic semiconductors and oxides," Journal of Applied Physics, vol. 93, no. 1, pp. 1-13, 2003.

[3] H. Akinaga and H. Ohno, "Semiconductor spintronics," IEEE Transactions on Nanotechnology, vol. 1, no. 1, pp. 19-31, 2002.

[4] T. Dietl, "Ferromagnetic semiconductors," Semiconductor Science and Technology, vol. 17, no. 4, p. 377, 2002.
[5] I. Malajovich, J. J. Berry, N. Samarth, and D. D. Awschalom, "Persistent sourcing of coherent spins for multifunctional semiconductor spintronics," Nature, vol. 411, no. 6839, pp. 770-772, 2001.

[6] H. Ohno, "Making nonmagnetic semiconductors ferromagnetic," Science, vol. 281, no. 5379, pp. 951-956, 1998.

[7] X. Xu, C. Cao, and Z. Chen, "Effects of temperature and atmosphere on the magnetic properties of Co-doped $\mathrm{ZnO}$ rods," Journal of Magnetism and Magnetic Materials, vol. 323, no. 14, pp. 1886-1889, 2011.

[8] S. Pearton, D. Norton, K. Ip, Y. Heo, and T. Steiner, "Recent progress in processing and properties of $\mathrm{ZnO}$," Progress in Materials Science, vol. 50, no. 3, pp. 293-340, 2005.

[9] H. Yan, J. Johnson, M. Law et al., "ZnO nanoribbon microcavity lasers," Advanced Materials, vol. 15, no. 22, pp. 1907-1911, 2003.

[10] S. J. Pearton, D. P. Norton, K. Ip, Y. W. Heo, and T. Steiner, "Recent progress in processing and properties of $\mathrm{ZnO}$," Progress in Materials Science, vol. 50, no. 3, pp. 293-340, 2005.

[11] K. Sato and H. Katayama-Yoshida, "Ferromagnetism in a transition metal atom doped ZnO," Physica E, vol. 10, no. 1-3, pp. 251-255, 2001.

[12] Y. Li, M. Zhu, T. Yang, J. Huang, H. Jin, and Y. Hu, "Structure and magnetic properties of $\mathrm{Cr}$-doped $\mathrm{ZnO}$ nanoparticles prepared under high magnetic field," Solid State Communications, vol. 150, no. 15-16, pp. 751-754, 2010.

[13] J. Huang, M. Zhu, Y. Li, T. Yang, H. Jin, and Y. Hu, "Fabricating Co doped $\mathrm{ZnO}$ nanocrystallines by hydrothermal method with high pulsed magnetic field," Journal of Nanoscience and Nanotechnology, vol. 10, no. 11, pp. 7303-7306, 2010.

[14] T. Yang, Y. Li, M. Zhu et al., "Room-temperature ferromagnetic Mn-doped $\mathrm{ZnO}$ nanocrystal synthesized by hydrothermal method under high magnetic field," Materials Science and Engineering B, vol. 170, pp. 129-132, 2010.

[15] L. Zhuge, X. Wu, Z. Wu, X. Chen, and Y. Meng, "Effect of defects on room-temperature ferromagnetism of $\mathrm{Cr}$-doped $\mathrm{ZnO}$ films," Scripta Materialia, vol. 60, no. 4, pp. 214-217, 2009.

[16] L. Schneider, S. V. Zaitsev, W. Jin et al., "Fabrication and analysis of $\mathrm{Cr}$-doped $\mathrm{ZnO}$ nanoparticles from the gas phase," Nanotechnology, vol. 20, no. 13, Article ID 135604, 2009.

[17] B. Wang, J. Iqbal, X. Shan et al., "Effects of Cr-doping on the photoluminescence and ferromagnetism at room temperature in $\mathrm{ZnO}$ nanomaterials prepared by soft chemistry route," Materials Chemistry and Physics, vol. 113, no. 1, pp. 103-106, 2009.

[18] I. Satoh and T. Kobayashi, "Magnetic and optical properties of novel magnetic semiconductor $\mathrm{Cr}$-doped $\mathrm{ZnO}$ and its application to all oxide p-i-n diode," Applied Surface Science, vol. 216, pp. 603-606, 2003.

[19] S. Singh, E. S. Kumar, and M. S. R. Rao, "Microstructural, optical and electrical properties of Cr-doped ZnO," Scripta Materialia, vol. 58, no. 10, pp. 866-869, 2008.

[20] Y. Liu, J. Yang, Q. Guan et al., "Effects of Cr-doping on the optical and magnetic properties in $\mathrm{ZnO}$ nanoparticles prepared by sol-gel method," Journal of Alloys and Compounds, vol. 486, no. 1-2, pp. 835-838, 2009.

[21] R. Bhargava, P. K. Sharma, S. Kumar, A. C. Pandey, and N. Kumar, "Consequence of doping mediated strain and the activation energy on the structural and optical properties of ZnO:Cr nanoparticles," Journal of Solid State Chemistry, vol. 183, no. 6, pp. 1400-1408, 2010. 
[22] J. M. D. Coey, M. Venkatesan, and C. B. Fitzgerald, "Donor impurity band exchange in dilute ferromagnetic oxides," Nature Materials, vol. 4, no. 2, pp. 173-179, 2005.

[23] N. H. Hong, J. Sakai, N. T. Huong, N. Poirot, and A. Ruyter, "Role of defects in tuning ferromagnetism in diluted magnetic oxide thin films," Physical Review B, vol. 72, no. 4, Article ID 045336, 5 pages, 2005.

[24] M. Venkatesan, C. B. Fitzgerald, J. G. Lunney, and J. M. D. Coey, "Anisotropic ferromagnetism in substituted zinc oxide," Physical Review Letters, vol. 93, no. 17, Article ID 177206, 4 pages, 2004.

[25] J. B. Wang, G. J. Huang, X. L. Zhong, L. Z. Sun, Y. C. Zhou, and E. H. Liu, "Raman scattering and high temperature ferromagnetism of Mn-doped $\mathrm{ZnO}$ nanoparticles," Applied Physics Letters, vol. 88, no. 25, Article ID 252502, 3 pages, 2006.

[26] C. Sudakar, P. Kharel, G. Lawes, R. Suryanarayanan, R. Naik, and V. M. Naik, "Raman spectroscopic studies of oxygen defects in Co-doped $\mathrm{ZnO}$ films exhibiting room-temperature ferromagnetism," Journal of Physics Condensed Matter, vol. 19, no. 2, Article ID 026212, 2007.

[27] J. Ye, S. Gu, S. Zhu et al., "Raman study of lattice dynamic behaviors in phosphorus-doped $\mathrm{ZnO}$ films," Applied Physics Letters, vol. 88, no. 10, Article ID 101905, 3 pages, 2006.

[28] K. Samanta, P. Bhattacharya, R. S. Katiyar, W. Iwamoto, P. G. Pagliuso, and C. Rettori, "Raman scattering studies in dilute magnetic semiconductor $\mathrm{Zn}_{1-x} \mathrm{Co}_{x} \mathrm{O}$," Physical Review $B$, vol. 73, no. 24, Article ID 245213, 2006.

[29] D. Mead and G. Wilkinson, "The temperature dependence of the raman effect in some wurtzite type crystals," Journal of Raman Spectroscopy, vol. 6, no. 3, pp. 123-129, 1977.

[30] L. Yang, X. Wu, G. Huang, T. Qiu, and Y. Yang, "In situ synthesis of $\mathrm{Mn}$-doped $\mathrm{ZnO}$ multileg nanostructures and Mn-related Raman vibration," Journal of Applied Physics, vol. 97, no. 1, Article ID 014308, 4 pages, 2005.

[31] X. Wang, S. Yang, J. Wang et al., "Nitrogen doped ZnO film grown by the plasma-assisted metal-organic chemical vapor deposition," Journal of Crystal Growth, vol. 226, no. 1, pp. 123129, 2001.

[32] K. R. Kittilstved, D. A. Schwartz, A. C. Tuan, S. M. Heald, S. A. Chambers, and D. R. Gamelin, "Direct kinetic correlation of carriers and ferromagnetism in $\mathrm{Co}^{2+}: \mathrm{ZnO}$," Physical Review Letters, vol. 97, no. 3, Article ID 037203, 4 pages, 2006.

[33] Z. Jin, T. Fukumura, M. Kawasaki et al., "High throughput fabrication of transition-metal-doped epitaxial $\mathrm{ZnO}$ thin films: a series of oxide-diluted magnetic semiconductors and their properties," Applied Physics Letters, vol. 78, no. 24, pp. 38243826, 2001. 

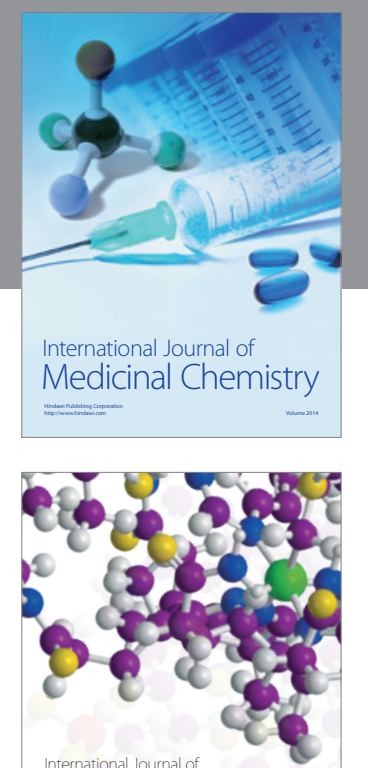

\section{Carbohydrate} Chemistry

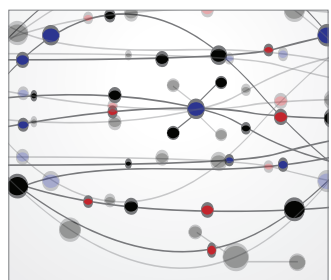

The Scientific World Journal
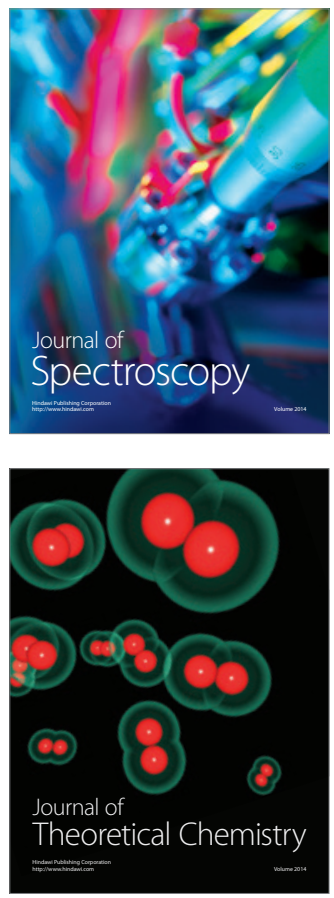
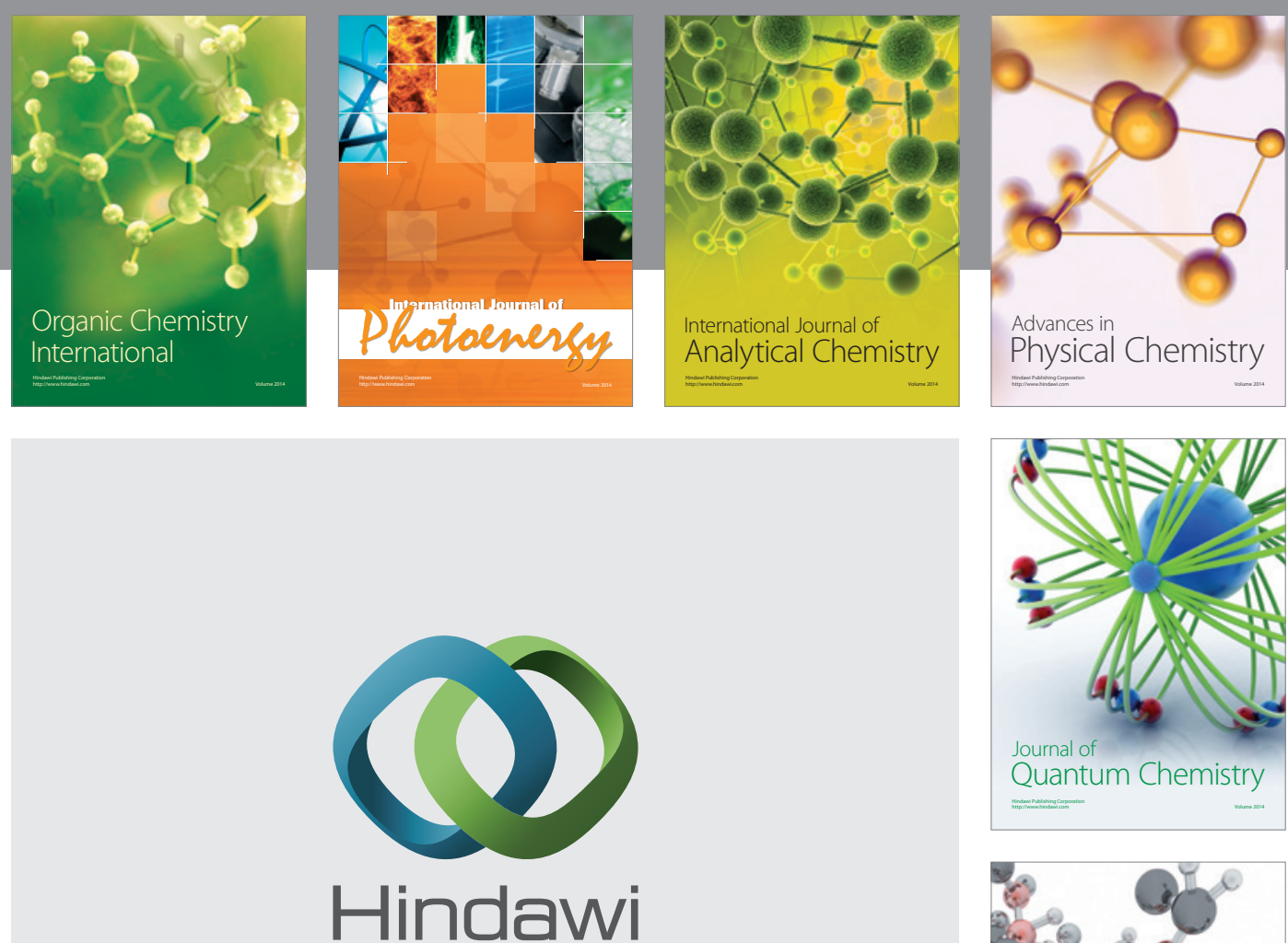

Submit your manuscripts at

http://www.hindawi.com

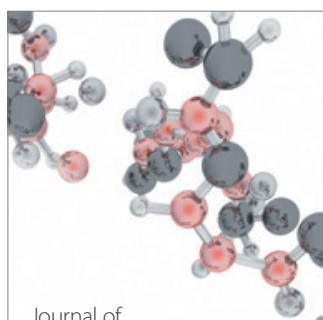

Analytical Methods

in Chemistry

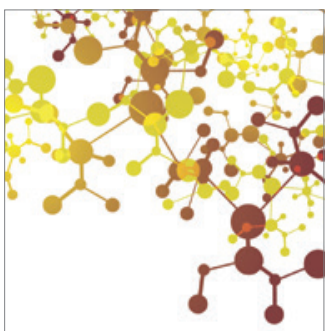

Journal of

Applied Chemistry

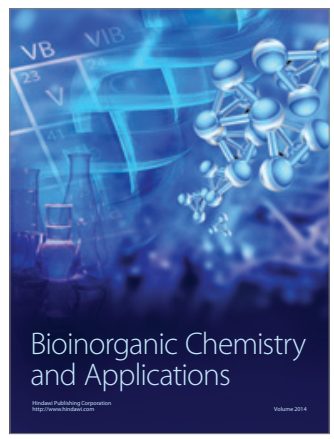

Inorganic Chemistry
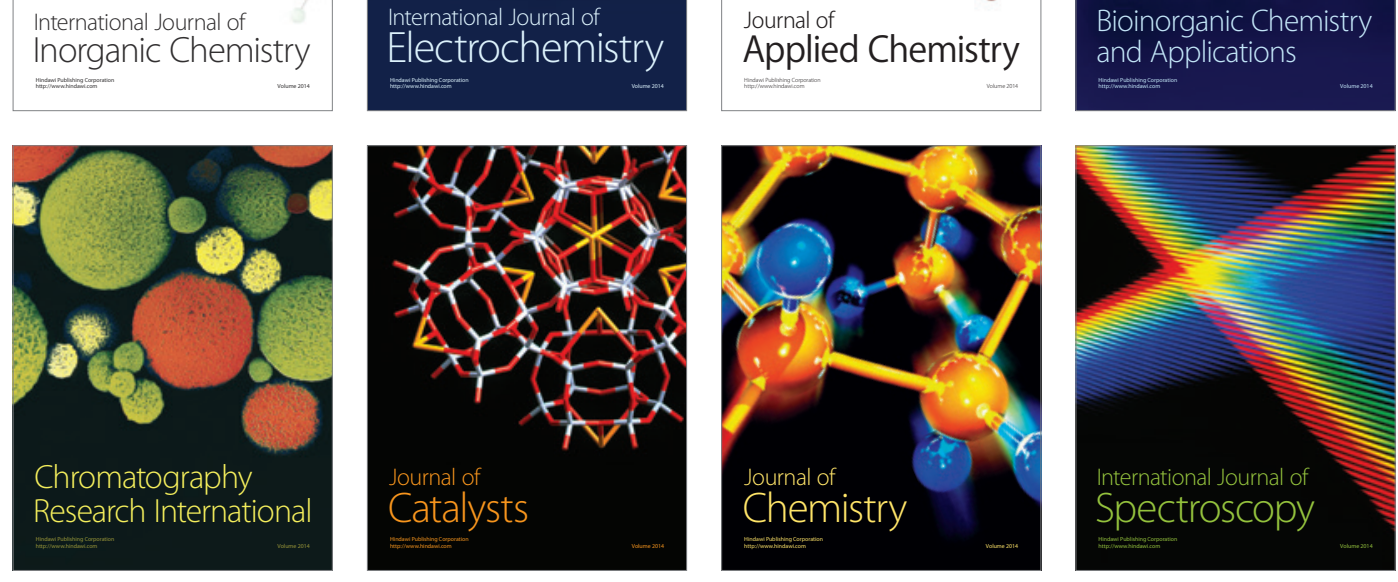